\title{
A Case of Postoperative Recurrent Lumbar Disc Herniation Conservatively Treated with Novel Intradiscal Condoliase Injection
}

\author{
Toru Funayama $\mathbb{D}^{1},{ }^{1}$ Yusuke Setojima, ${ }^{2}$ Yosuke Shibao $\mathbb{D}^{1},{ }^{1}$ Hiroshi Noguchi, ${ }^{1}$ \\ Kousei Miura $\mathbb{D}^{1}{ }^{1}$ Fumihiko Eto, ${ }^{1}$ Kosuke Sato, ${ }^{1}$ Mamoru Kono, ${ }^{1}$ Tomoyuki Asada, ${ }^{1}$ \\ Hiroshi Takahashi $\mathbb{D}^{1}{ }^{1}$ Masaki Tatsumura, ${ }^{3}$ Masao Koda, ${ }^{1}$ and Masashi Yamazaki $\mathbb{D}^{1}$ \\ ${ }^{1}$ Department of Orthopaedic Surgery, Faculty of Medicine, University of Tsukuba, 1-1-1 Tennoudai, Tsukuba, \\ 3058575 Ibaraki, Japan \\ ${ }^{2}$ Department of Orthopaedic Surgery, Kenpoku Medical Center Takahagi Kyodo Hospital, 1006-9, Ageho-cho, Kamitetsuna, \\ Takahagi, 318-0004 Ibaraki, Japan \\ ${ }^{3}$ Department of Orthopaedic Surgery and Sports Medicine, Tsukuba University Hospital Mito Clinical Education and Training \\ Center/Mito Kyodo General Hospital, 3-2-7 Miyamachi, Mito, 310-0015 Ibaraki, Japan
}

Correspondence should be addressed to Toru Funayama; funatoru3@gmail.com

Received 31 May 2021; Revised 6 September 2021; Accepted 31 January 2022; Published 15 February 2022

Academic Editor: Eyal Itshayek

Copyright (c) 2022 Toru Funayama et al. This is an open access article distributed under the Creative Commons Attribution License, which permits unrestricted use, distribution, and reproduction in any medium, provided the original work is properly cited.

\begin{abstract}
Although postoperative recurrent lumbar disc herniation (rec-LDH) is uncommon, it is a challenging situation that requires revision surgery when conservative treatment fails. Recently, an agent inducing chemical dissolution of the nucleus pulposus using condoliase has been approved as a novel intradiscal treatment for LDH. To date, no evidence has been reported regarding its effectiveness in the treatment of postoperative rec-LDH. A 25-year-old man with a history of LDH in L4/5, who underwent transforaminal full endoscopic lumbar discectomy when he was 17 years old, complained of severe pain radiating to his left leg since 1 month. The straight leg-raising test was limited to $25^{\circ}$ on the left side. Lumbar T2-weighted magnetic resonance imaging (MRI) showed intracanal, left-sided transligamentous disc herniation at L4/5 with high-signal intensity. Because the conservative treatment with oral analgesics and selective left L5 nerve root block failed, the patient requested intradiscal condoliase injection instead of revision surgery. There were no adverse events reported after the condoliase treatment, and the pain radiating to the left leg improved within 2 weeks. A lumbar MRI performed 2 months after treatment revealed that the disc herniation had significantly decreased in size. The straight leg-raising test examined 3 months after treatment was negative. In this case, the disc herniation was of the transligamentous type and showed a high-signal intensity on T2-weighted MRI which could be suitably treated by condoliase injection therapy. This case report is the first to suggest that intradiscal condoliase injection could be a useful and novel conservative treatment option to treat postoperative rec-LDH.
\end{abstract}

\section{Introduction}

Postoperative recurrent lumbar disc herniation (rec-LDH) is a challenging condition [1] and accounts for 3-9.3\% of cases after transforaminal full endoscopic lumbar discectomy (FELD) [2-4], similar to that of microendoscopic discect- omy [5]. Due to compression of the traversing spinal nerve root, revision surgery should be considered for rec-LDH when conservative treatment fails [1].

An agent that induces the chemical dissolution of the nucleus pulposus using condoliase (Hernicore ${ }^{\circledR}$, Kaken Pharmaceutical Co.) [6] was recently approved as a novel 


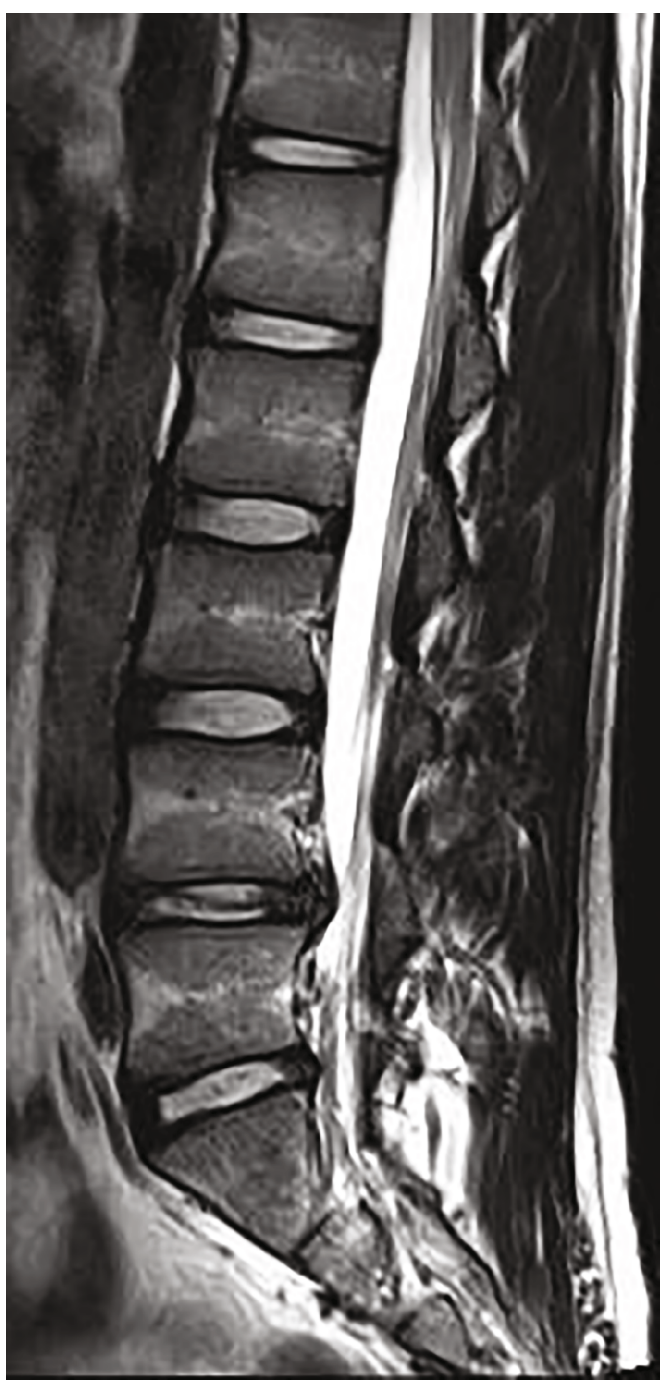

(a)

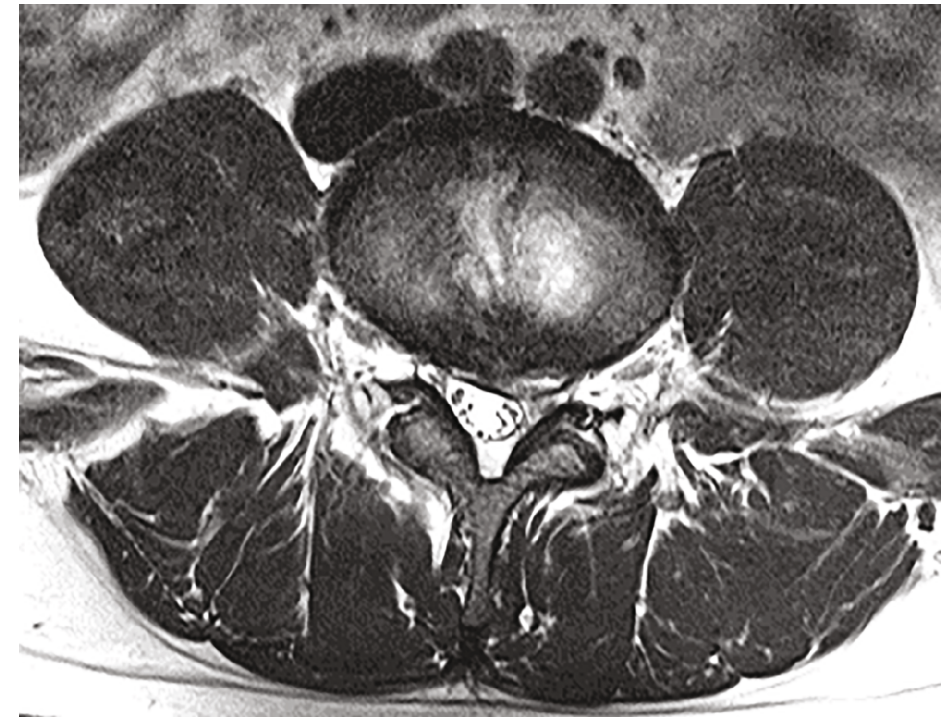

(b)

FIGURE 1: Magnetic resonance imaging before transforaminal full endoscopic lumbar discectomy 8 years ago. A (a) sagittal section and (b) horizontal section of the L4/5 showed subligamentous lumbar disc herniation. 


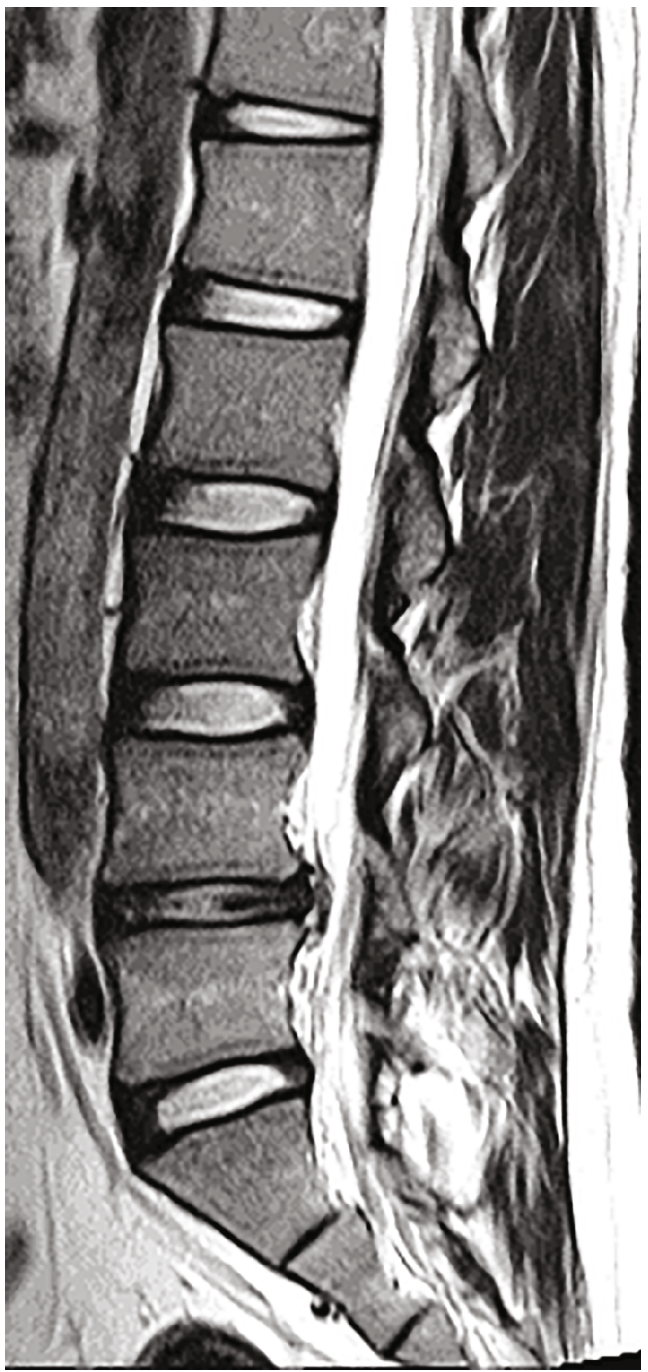

(a)

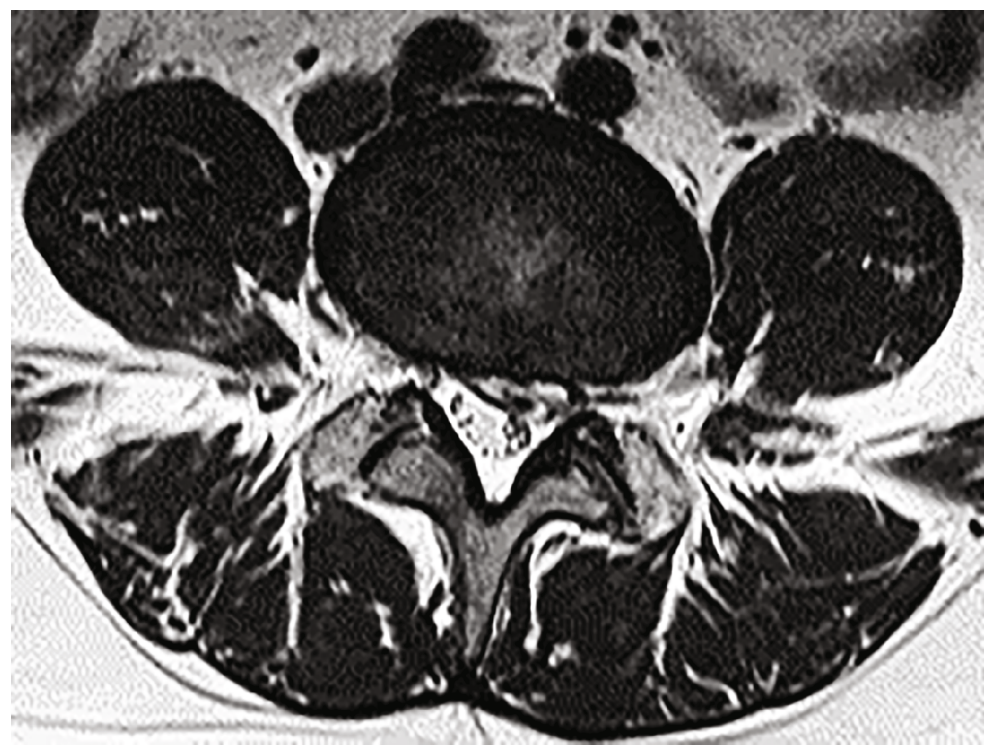

(b)

FIGURe 2: Continued. 


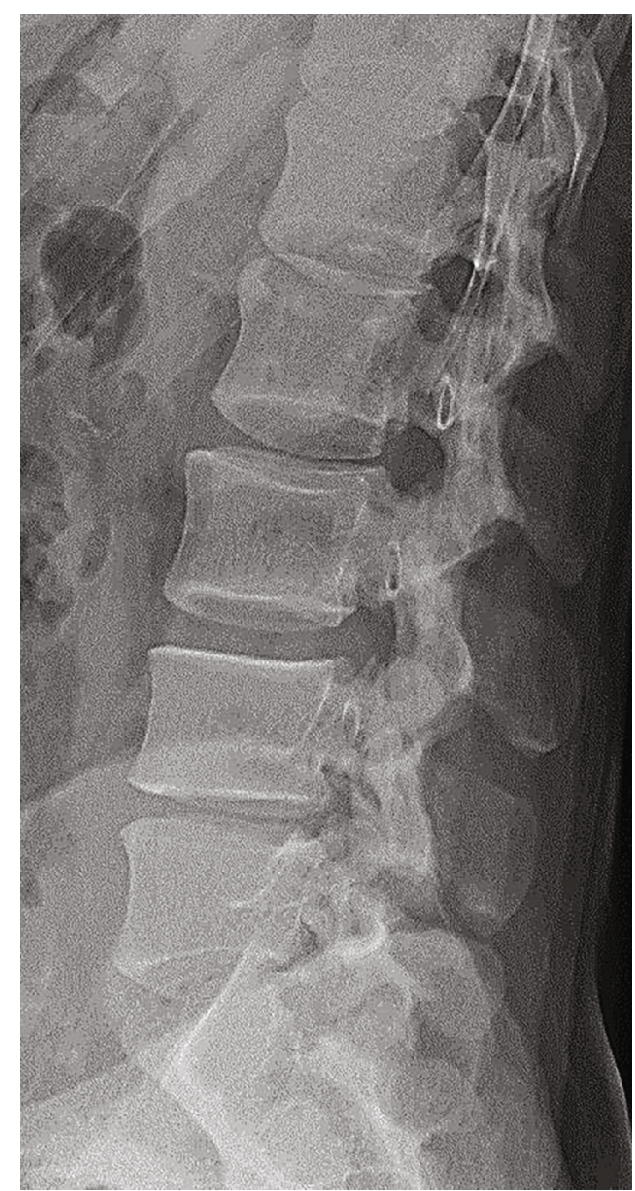

(c)

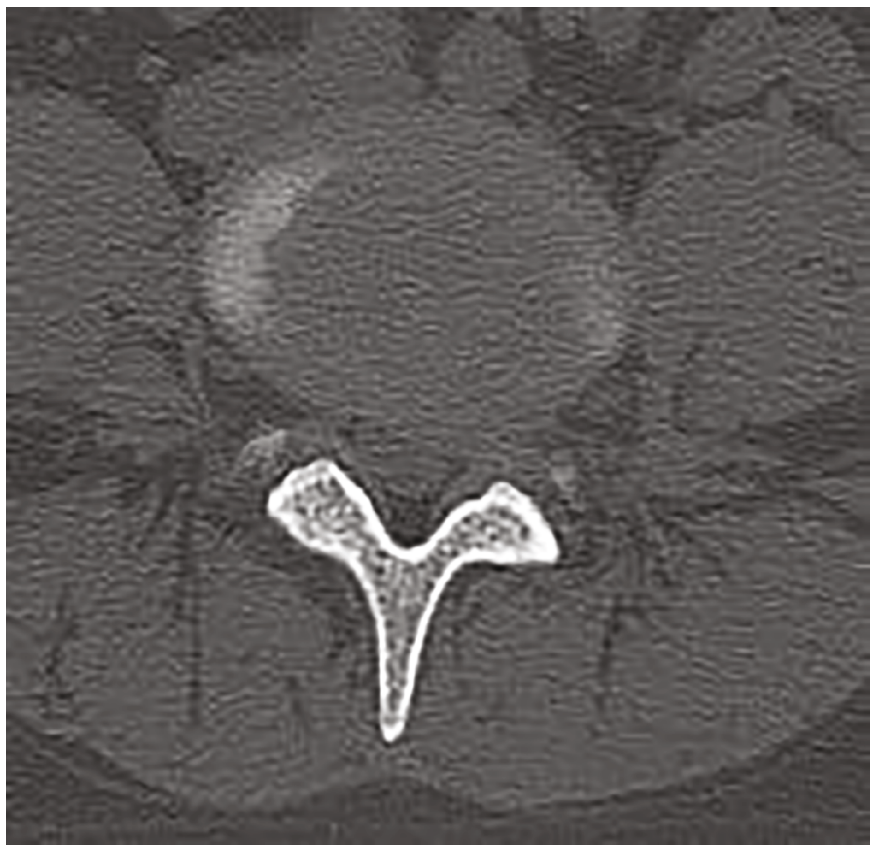

(d)

FIgURE 2: Spinal imaging before intradiscal condoliase injection. A (a) sagittal section and (b) horizontal section of the L4/5 on T2-weighted magnetic resonance imaging showed intracanal, left-sided transligamentous disc herniation with high-signal intensity. (a) The degree of affected disc degeneration was grade III according to the Pfirrmann classification [9]. (c) Standing radiography revealed that the L4/5 disc height was slightly diminished as compared to the other discs. (d) Computed tomography showed no bony stenosis at L4/5. 


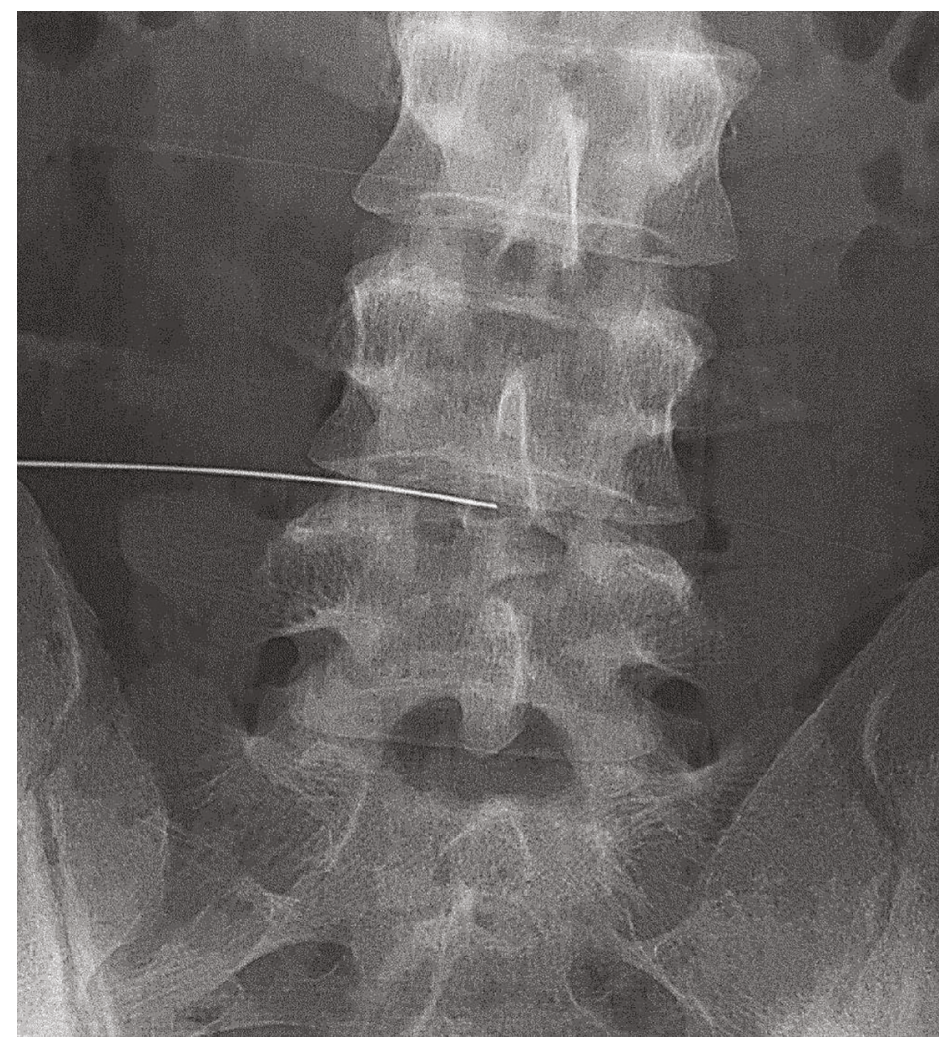

(a)

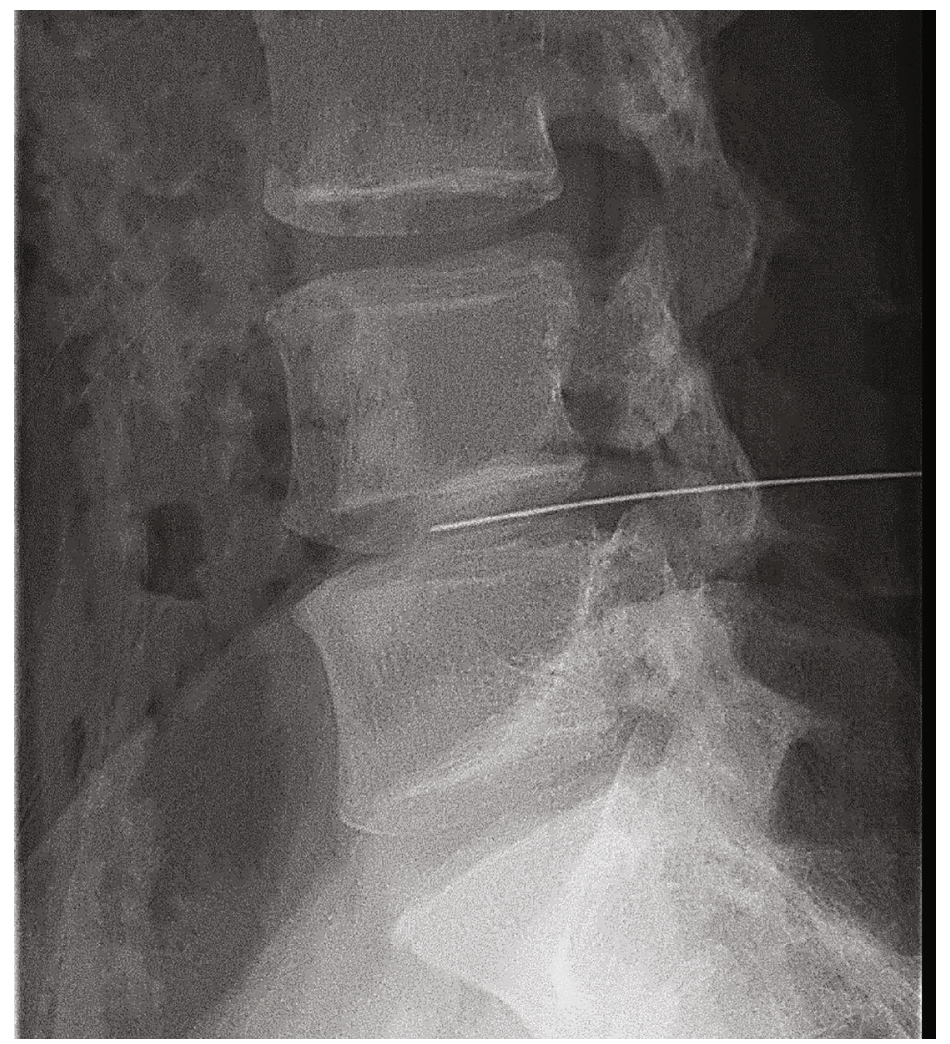

(b)

Figure 3: Continued. 


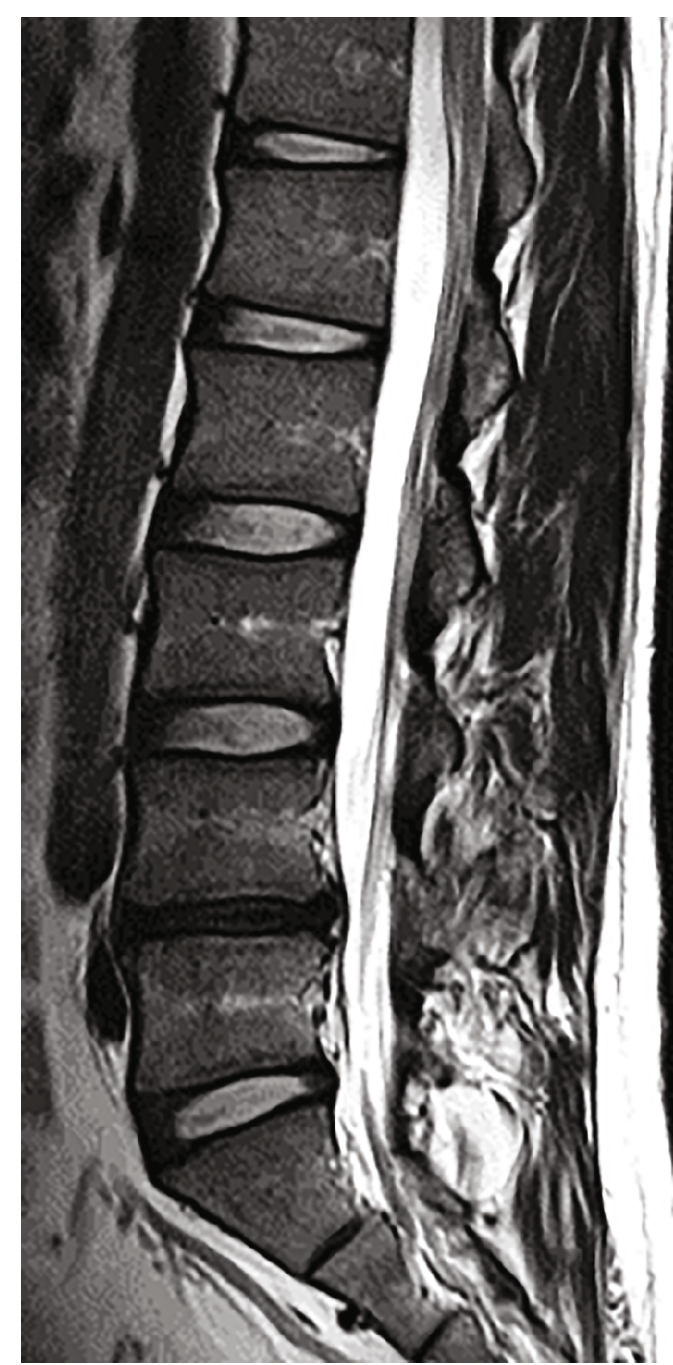

(c)

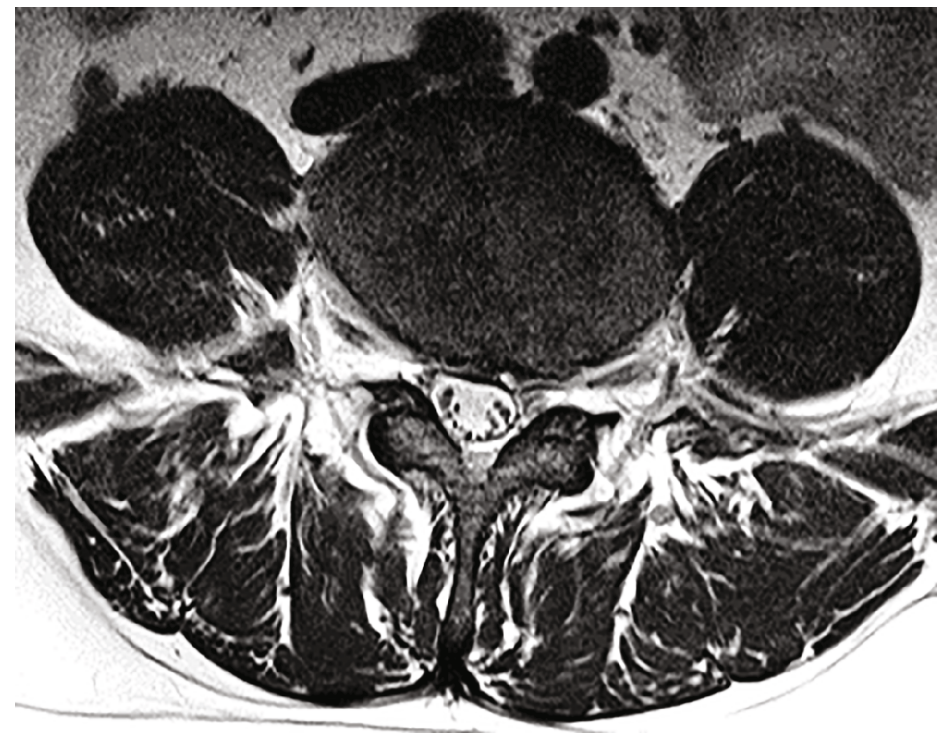

(d)

Figure 3: Continued. 


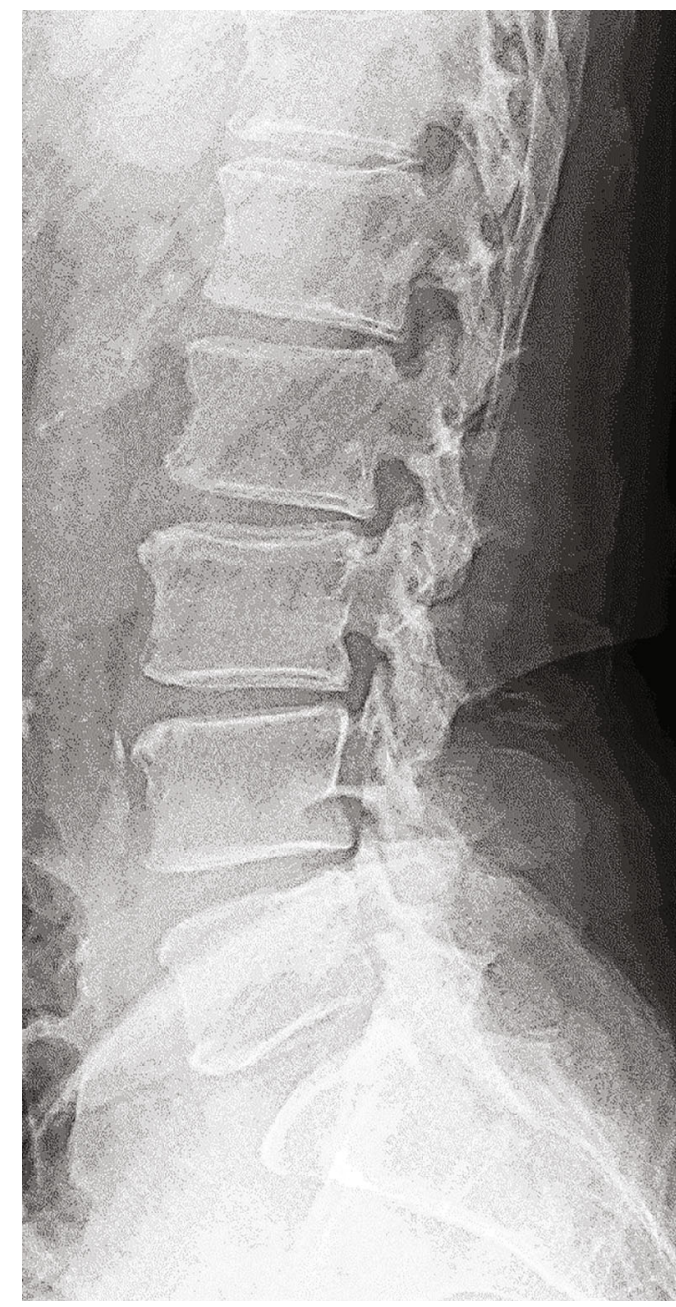

(e)

Figure 3: Condoliase injection procedure and findings after treatment. In the prone position, a $12 \mathrm{~cm}$ spinal needle was inserted from the left lateral side under fluoroscopy, advanced to the center of the L4/5 disc (a, b), and the condoliase was injected. Two months after treatment, lumbar T2-weighted magnetic resonance imaging showed that the disc herniation at L4/5 had significantly decreased in size $(c, d)$. Although progression of the degree of affected-disc degeneration was observed (c), standing radiography revealed that the L4/5 disc height was the same as that before treatment $(\mathrm{e})$.

intradiscal treatment for LDH $[7,8]$. However, no evidence has been reported regarding its effectiveness in the treatment of postoperative rec-LDH in the English literature to date.

\section{Case Presentation}

A 25-year-old man with a history of LDH in L4/5, who had previously undergone transforaminal FELD at our institute at the age of 17 years (Figures 1(a) and 1(b)), complained of severe pain radiating to his left leg since 1 month. He had received a selective left L5 nerve root block at another hospital 10 days prior. Although his leg pain disappeared immediately after the block, it returned on the same night. He was an office worker at a sales position but had to be absent from work due to the pain. Physical examination revealed normal patellar and Achilles tendon reflexes on both sides, and manual muscle testing and lower limb sensations were normal. The pain was absent when he was seated at rest but intensified when he stood up or walked. The straight leg-raising test (SLRT) was positive and limited to $25^{\circ}$ on the left, whereas the femoral nerve stretch test was negative on both sides. The Japanese Orthopaedic Association (JOA) score was 16 out of 29 points. The JOA Back Pain Evaluation Questionnaire (JOABPEQ) scores out of 100 for low back pain, lumbar function, walking ability, social life function, and mental health were $0,0,0,8$, and 41 , respectively. The visual analog scale (VAS) scores out of 10 for low back pain, leg pain, and leg numbness were 9 each.

Lumbar T2-weighted MRI showed intracanal, left-sided transligamentous disc herniation at L4/5 with high-signal intensity (Figures 2(a) and 2(b)). The degree of affecteddisc degeneration was grade III according to the Pfirrmann classification [9] (Figure 2(a)). Standing radiography revealed that the L4/5 disc height had diminished slightly as compared to the other discs (Figure 2(c)). Computed tomography showed no bony stenosis (Figure 2(d)). 
Because oral pregabalin $(300 \mathrm{mg} /$ day $)$, tramadol hydrochloride/acetaminophen (37.5 mg/325 mg; 3 tablets/day) and selective nerve root block showed poor analgesic effects in the patient, the L5 radiculopathy was considered resistant to conservative treatment. Although we informed the patient that there was no evidence regarding the effectiveness of intradiscal condoliase injection in the treatment of postoperative rec-LDH, the patient requested it instead of revision surgery. In the prone position, a $12 \mathrm{~cm}$ spinal needle was inserted from the left lateral side under fluoroscopy, advanced to the center of the L4/5 disc, and $1.25 \mathrm{U}$ of condoliase dissolved in $1.2 \mathrm{~mL}$ of physiological saline was injected (Figures 3(a) and 3(b)).

No adverse events were reported after the treatment, and the pain radiating to the left leg improved within 2 weeks. Two months after treatment, the lumbar T2-weighted MRI showed that the disc herniation at L4/5 had significantly decreased in size (Figures 3(c) and 3(d)). Although progression of the degree of affected-disc degeneration was observed (Figure 3(c)), standing radiography revealed that the L4/5 disc height was the same as that before treatment (Figure 3(e)). Three months after treatment, the SLRT was negative on both sides, and the JOA score improved to 26 out of 29 points. The JOABPEQ scores out of 100 for low back pain, lumbar function, walking ability, social life function, and mental health were $100,75,86,54$, and 57 , respectively, and the VAS scores out of 10 for low back pain, leg pain, and leg numbness were 2, 3, and 3, respectively, thus showing significant improvements in all parameters.

\section{Discussion}

Condoliase injected into an intervertebral disc specifically dissolves glycosaminoglycans, which constitute proteoglycans, the main component of the nucleus pulposus [6]. This reduces the water-holding capacity of the proteoglycans, reduces the pressure inside the intervertebral disc, lowers the pressure on the nerve root from the hernia, and leads to improvement in the lower extremity and low back pain [7].

A previous study observed significant analgesic effects in $85.4 \%$ of the patients [10], improved lumbar function, and improved quality of life as compared to the placebo treatment in intracanal LDH cases [8]. Additionally, a recent report of condoliase injection showed good results for lateral LDH [11]. Other studies concluded that condoliase injection seems to be the most effective treatment option for the transligamentous type of $\mathrm{LDH}$ [12] and herniation showing highsignal intensity on T2-weighted MRI $[12,13]$.

This is the first report on the effectiveness of condoliase injections in treating postoperative rec-LDH and avoiding the need for revision surgery. In this case, conservative therapy with oral medications and selective nerve root block was unsuccessful. However, intradiscal condoliase injection proved effective, achieving an analgesic effect soon after treatment, which was not inferior to revision surgery [14]. The disc herniation of the present case was of the transligamentous type and showed high-signal intensity on the T2weighted MRI, which was suitable for condoliase injection therapy for nonoperated LDH $[12,13]$.
Although more findings from comparative studies or large case series including various surgical methods other than transforaminal FELD are needed, this report suggests that intradiscal condoliase injection could be a useful and novel conservative treatment option with a possibility of avoiding the need for revision surgery in postoperative rec-LDH.

\section{Conflicts of Interest}

The authors declare that there is no conflict of interest regarding the publication of this article.

\section{References}

[1] R. Ajiboye, A. Drysch, G. Mosich, A. Sharma, and S. Pourtaheri, "Surgical treatment of recurrent lumbar disk herniation: a systematic review and meta-analysis," Orthopedics, vol. 41, no. 4, pp. e457-e469, 2018.

[2] H. Shi, L. Zhu, Z. Jiang, and X. T. Wu, "Radiological risk factors for recurrent lumbar disc herniation after percutaneous transforaminal endoscopic discectomy: a retrospective matched case-control study," European Spine Journal, vol. 30, no. 4, pp. 886-892, 2021.

[3] M. Kong, D. Xu, C. Gao et al., "Risk factors for recurrent L4-5 disc herniation after percutaneous endoscopic transforaminal discectomy: a retrospective analysis of 654 cases," Risk Management and Healthcare Policy, vol. Volume 13, pp. 30513065, 2020.

[4] H. Kim, J. You, and C. Ju, "Predictive scoring and risk factors of early recurrence after percutaneous endoscopic lumbar discectomy," BioMed Research International, vol. 2019, Article ID 6492675, 2019.

[5] J. Xu, Y. Li, B. Wang et al., "Minimum 2-year efficacy of percutaneous endoscopic lumbar discectomy versus microendoscopic discectomy: a meta-analysis," World Neurosurgery, vol. 138, pp. 19-26, 2020.

[6] Y. Matsuyama and K. Chiba, "Condoliase for treatment of lumbar disc herniation," Drugs Today, vol. 55, no. 1, pp. 1723, 2019.

[7] Y. Matsuyama, K. Chiba, H. Iwata, T. Seo, and Y. Toyama, "A multicenter, randomized, double-blind, dose-finding study of condoliase in patients with lumbar disc herniation," Journal of Neurosurgery. Spine, vol. 28, no. 5, pp. 499-511, 2018.

[8] K. Chiba, Y. Matsuyama, T. Seo, and Y. Toyama, "Condoliase for the treatment of lumbar disc herniation: a randomized controlled trial," Spine, vol. 43, no. 15, pp. E869-E876, 2018.

[9] C. Pfirrmann, A. Metzdorf, M. Zanetti, J. Hodler, and N. Boos, "Magnetic resonance classification of lumbar intervertebral disc degeneration," Spine, vol. 26, no. 17, pp. 1873-1878, 2001.

[10] E. Okada, S. Suzuki, S. Nori et al., "The effectiveness of chemonucleolysis with condoliase for treatment of painful lumbar disc herniation," Journal of Orthopaedic Science, vol. 26, no. 4, pp. 548-554, 2021.

[11] T. Funayama, K. Mataki, K. Murakami et al., "Two cases of lateral lumbar disc herniation successfully treated with intradiscal condoliase injection," Spine Surgery and Related Research, vol. 5, no. 6, pp. 437-441, 2021.

[12] T. Banno, T. Hasegawa, Y. Yamato et al., "Clinical outcome of condoliase injection treatment for lumbar disc herniation: 
indications for condoliase therapy," Journal of Orthopaedic Science, vol. 26, no. 1, pp. 79-85, 2021.

[13] K. Ishibashi, M. Fujita, Y. Takano, H. Iwai, H. Inanami, and H. Koga, "Chemonucleolysis with chondroitin sulfate ABC endolyase for treating lumbar disc herniation: exploration of prognostic factors for good or poor clinical outcomes," Medicina, vol. 56, no. 11, p. 627, 2020.

[14] Y. Yao, H. Zhang, J. Wu et al., "Comparison of three minimally invasive spine surgery methods for revision surgery for recurrent herniation after percutaneous endoscopic lumbar discectomy," World Neurosurgery, vol. 100, pp. 641-647.e1, 2017. 